\title{
How streetcars shaped suburbanization: a Granger causality analysis of land use and transit in the Twin Cities
}

Feng Xie* and David Levinson**

\begin{abstract}
This article presents a Granger causality analysis of the coupled development of population and streetcars in the Twin Cities of Minneapolis and St Paul Historic residence and network data were assembled for 1900-1930, and linear crosssectional time-series models were estimated at both a tract and block level using these data. It is found that, in contrast with transportation systems that were expanded in response to increased demand, the rapid expansion of the streetcar system during the electric era has been driven by other forces and to a large extent led land development in the Twin Cities. The main forces that have driven this process include technological superiority, monopoly, close connections with real estate business and people's reliance on the streetcar for mobility. Proximity to the streetcar is found to be a crucial factor that determines the distribution and development of residences: it is observed that residential density declines with the distance from streetcar lines, and significantly drops beyond a walkable distance; it is also observed that gaining a closer access to streetcar lines within $800 \mathrm{~m}$ (about a half mile) predicts the increase in residential density to a significant extent.
\end{abstract}

Keywords: transit, land use, suburbanization, Granger Causality, Twin Cities

JEL classifications: N92, R20, R40

Date submitted: 23 August 2008 Date accepted: 5 June 2009

\section{Introduction}

The story of every urban transportation system has been a product of the geography and demographics of its surrounding region, while the development of transportation systems has in turn transformed the cities and communities they serve. In the 1960s, geographers recognized the marked role of land use-transport interactions in the formation and differentiation of places and transportation networks. ${ }^{1}$ Since the 1980 s, integrated land use-transport modeling has gained its momentum and seen widespread

*Department of Civil Engineering, University of Minnesota, 500 Pillsbury Drive SE, Minneapolis, MN 55455, USA. email<xiex0055@umn.edu>

**RP Braun-CTS Chair of Transportation Engineering, Department of Civil Engineering, University of Minnesota, 500 Pillsbury Drive SE, Minneapolis, MN. email < dlevinson@umn.edu>

1 Taaffe et al. (1963), for instance, has proposed a conceptual model to describe the staged process of colonial exploitation proceeding from the coastal baseline to the inland area: penetration roads are first built from interior to reach selected ports; while connected ports and the inland feeders grew due to increased trading, new places emerged on the penetration lines, leading to another round of road additions that interconnect developed places. 
application in urban planning and design. ${ }^{2}$ Accessibility, defined as the ease of reaching valued activities, has long been recognized as one of the key concepts that connect transportation and land use and explain regional form and distribution of population and employment (Wachs and Kumagai, 1973; Axhausen, 2008; Scott and Horner, 2008).

In empirical research, the relationship between transportation and land use has been widely examined as a two-way process by which one is the driver of the other. A fraction of this literature focused on the Granger causality between land use and transport development. ${ }^{3}$ Using county-level data in the US Mid-Atlantic Region, Fulton et al. (2000) estimated cross-sectional time-series models that relate daily vehicle miles of travel (VMT) to roadway capacity in lane-miles. The results indicated that growth in lane-miles preceded growth in VMT. Cervero and Hansen (2002), presenting simultaneous models that predict induced VMT and lane-miles on roads using 22 years of observations for 34 California urban counties, found strong reciprocal relationships between road investment and travel demand. While the reciprocal relationship is pervasive, induced supply and induced demand may exhibit different strengths in different transportation systems. The reasons for the difference could be geographical, technological, economic, managerial, social or political. Levinson (2007), analyzing the co-development of rail and population in London since 1871, found that the feedback effects between population density and rail density are distinct in the core and periphery of the city; rails helped depopulate the center (where houses were replaced with jobs) and populate the periphery. Corbett et al. (2009) disclosed that the addition of skyway connections in downtown Minneapolis follow a mathematical path by which the accessibility to the activities in the connected buildings (measured by constructed area in square feet) would be maximized. Skyway deployment has largely followed rather than led downtown establishments probably because it is a lot less costly to add a skyway than to construct new office space in the dense city center. Similarly, the interurban railways in North America were deployed in large part connecting the established cities and towns (Hilton and Due, 1960). The coupled population growth in cities connected by interurbans was not as significant probably because the system was abandoned so quickly. ${ }^{4}$ Warner (2004), using Boston 1870-1900 as a case study, described how the streetcar had led the process of suburbanization in American cities during the Gilded Age.

The streetcar system in the Twin Cities of Minneapolis and St Paul provides another example. Over the period from the 1870 s to the 1950 s, the system had been a significant force in the growth and shape of the Twin Cities. Starting from two primitive horsecar lines in 1875, it had developed into one of the world's finest urban transportation systems over the course of the 20 century. In the 1910s, the electrified streetcars provided nearly $100 \%$ of all public transportation in the Twin Cities.

2 Refer to Timmermans (2003) or Iacono et al. (2008) for comprehensive surveys of this literature.

3 A question that frequently arises in time series analysis is whether or not one variable can help forecast another variable. First introduced by Granger (1969), the Granger causality test involves using F-tests to test whether lagged information on a time-series variable $\mathrm{X}$ provides any statistically significant information about another variable Y. In particular, the Granger causality between land use and transportation examines whether land use development leads to the future deployment of transportation infrastructure, or vice versa. Limitations of Granger causality analysis are discussed in Section 6.

4 The Indiana interurban system, for example, was built mainly between 1901 and 1908; the network started to decline in about 1918, and was completely abandoned within two decades. 
At its peak, the system carried over 200 million passengers each year beween 1919 and 1925 and reached its greatest extent, $842 \mathrm{~km}$ (523 miles) of track, in 1931. Diers and Isaacs (2006) recounted the streetcar era in the Twin Cities.

As Adams and VanDrasek (1993) pointed out in a brief recap of the Twin Cities streetcar history, population had first led, then followed the deployment of streetcar lines. Born in the 1840s, Minneapolis and St Paul had emerged on the frontier as important gateway cities and rail centers for people who moved west following the railroads. As the city grew, urban population expanded rapidly. The Federal Census reported 297,894 inhabitants for Minneapolis and St Paul combined in 1890 growing to 615,280 in 1920 , more than doubling over three decades. It became obvious that there had to be a faster and better way to move people than on foot or horseback. Following this demand, the first two horsecar lines were brought to Minneapolis in 1875 . Interestingly, the two most notable promoters of streetcars in the Twin Cities, Colonel King and Thomas Lowry ${ }^{5}$, were both actively involved in the real estate business. Colonel King had his farm and properties well outside Minneapolis's city limits, while Thomas Lowry developed many neighborhoods in Minneapolis, St Paul, and the surrounding communities. So it came as no surprise that they first introduced the streetcar in order to serve their outlying holdings and enhance their real estate value. As the city grew and people kept demanding public transportation services, they then built more streetcar lines at the interest of making more profits from the transit system. The system saw remarkable expansion from the initial $3.4 \mathrm{~km}(2.1 \mathrm{miles})$ of horsecar line in 1875 to $106 \mathrm{~km}$ (66 miles) by $1889 .^{6}$

The first electric streetcar line opened in Minneapolis on 24 December 1889. Faster and cheaper than horsecars, the technology of electric railway proved to be a great success. By the close of 1891, nearly all the streetcar lines had been converted to electric power. As the streetcar system grew, so did the Twin Cities. The extension of streetcar lines opened up vast land and parcels in the suburbs, leading to the expansion of city boundaries. Thomas Lowry sold lots and homes at the terminals and intersections where residences and businesses subsequently sprouted, and even built amusement parks at the end of streetcar lines to encourage recreational trips, making enormous profits from both enterprises. The streetcar system was so prosperous and profitable that TCRT eventually overbuilt the network. In fact, the rapid extension of streetcar lines was largely responsible for some of the lowest density development of residential area found among midwestern cities (Adams and VanDrasek, 1993).

This study presents a Granger causality analysis of streetcar deployment versus residential development in the electric streetcar era of the Twin Cities. Questions under scrutiny include whether streetcar extension and population growth exhibit causation effects with equal strength, and why one effect could gain the upper hand on the other. Based on empirical observations from the Twin Cities, this research aims to present evidence on the significant role the electrification of street railway played in fostering urban growth and shaping residential patterns in the metro area. The article proceeds as follows: the next section presents the hypothesis to be tested; data are then constructed

5 Thomas Lowry was the first president of Twin Cities Rapid Transit (TCRT), the monopoly runner of the Twin Cities streetcar system, and Colonel King was the initial organizer of Minneapolis Street Railway Company, the precursor of TCRT.

6 Before 1889 steam cars and steam-power cable cars were experimented with, but quickly failed. 
and models proposed, which is followed by a discussion of results; in the last section conclusions are drawn and their implications highlighted.

\section{Hypotheses}

The development of the Twin Cities trolley system demonstrated distinct characteristics in two different stages. The turning point was 1889 , when the transit lines were changed to electric power. Prior to 1889 , horsecar lines were deployed following a rapidly growing population; after 1889 the flourishing system extended into the open suburban land, leading to new residential development where streetcars reached. While most electric streetcar lines survived through 1954-1955 before being converted to bus routes, our analysis focuses only on the growth phase of the infrastructure, namely, 1889-1931. In review of the history, the rapid expansion of the Twin Cities streetcar system during this period had mainly been driven by three forces.

First, electric street railway technology was one of the most important inventions of the 19th century. As Diers and Isaacs (2006) stated, 'few events in Twin Cities history in the nineteenth century can compete in significance with the electrification of the street railway system and its subsequent effects on growth and development'. Compared with horsecars and steam-propelled streetcars, electric streetcars provide a faster and far more economical way to move people, while significant competition from internal combustion engine did not emerge until the 1910s and not in full force until the 1920s. The superiority of the electric street railway technology at that time had resulted in the pervasive optimism among entrepreneurs, ${ }^{7}$ and eventually led to the excessive expansion of the system.

Second, ownership structure played an important role in the deployment of the Twin Cities streetcar system. Unlike today's highways and transit systems, the streetcar system remained privately owned by a group of real estate investors and promoters. Their interest naturally led to the development of vast tracts of land where streetcar lines extended. When residential, commercial and recreational activities sprung following the lines, both streetcar ridership and real estate value increased. On the other hand, unlike in other cities such as Philadelphia and Chicago where independent streetcar companies were granted franchises and eventually consolidated, TCRC was regulated as a monopoly since its early stage of development and throughout the electric streetcar era. The exclusive franchise, though, was granted by the city councils subject to two conditions: the first required a flat fare of five cents, and the second was the councils' power to order the company to build any line which the councils declared reasonably necessary (Lowry, 1978). For many years, these requirements assured an affordable ride on an efficient system, which enabled working people to live outside the city centers and commute to work.

Third, as and then urban transportation was prevailing, the streetcar system perhaps provided the only means of public transportation for most working class people before 1930s. During this era, proximity to a streetcar line determined where people lived and where they worked. Being accessible to a streetcar is so crucial that the deployment of streetcar lines had produced 'finger-shaped extensions of residential areas' 
(Adams and VanDrasek, 1993) because 'it was easy to build outward along the lines but hard to expand between them'.

Based on the discussions above, it is posited that the extension of electric streetcar lines preceded the increase of residential density in neighborhoods reached by the streetcar. While we may also observe the causation effect in the opposite direction, that is, addition of streetcar lines in response to the increased demand (residences), we would expect the causation effect from the streetcar side to development is a stronger effect here. Rather than the demand, technological superiority, monopoly, close connections with real estate business and reliance on streetcars could be the major forces that drove the rapid expansion of the streetcar system.

Due to heavy reliance on the streetcar service and lack of complimentary transportation in this era (other than walking) that would feed the streetcar, living close to streetcar lines was crucial for people to get around for work and shopping at that time. We thus hypothesize that proximity to a streetcar line is the pivotal factor that determines the spatial distribution of residences. We expect to observe residential density declining outward along streetcar lines and significantly dropping beyond an affordable walking distance. It is also hypothesized that a neighborhood that gains closer access to the streetcar service (after new lines are opened) will see subsequent increases in residential density.

\section{Data}

\subsection{Network data}

Time series population and streetcar network data are essential to test our hypotheses. Metropolitan Council, the regional planning agency serving the Twin Cities sevencounty metropolitan area, has digitized in an ArcGIS shapefile all the historic transit routes of the region, referencing the book by Isaacs and Diers (2007) on the history of the Twin Cities streetcar lines. The shapes contain streetcar, horsecar, ferry, 1948 bus and steam power routes, from which all the streetcar lines were extracted for our analysis. In the data set, one shape and one corresponding record represents each route segment (Metropolitan Council, 2007). Attributes of each record include opening year, closing year, corridor name, etc. In the data there are 12 streetcar route segments whose opening dates are missing. We corrected the absent opening dates referring to Olson (1976), which includes a comprehensive review of construction and abandonment for each streetcar line in the Twin Cities.

\subsection{Population data}

Analysis of the relationship between population and streetcars requires historic population data during 1889-1931 at a sub-county level, which turned out to be a challenging task. Our first resort was census population statistics at the tract level. Since census tracts were not laid out in the Cities of Minneapolis and St Paul until 1934 (Green and Truesdell, 1937), census tract data are not available for the electric streetcar era. Another possibility is extracting data from various accounts of Twin Cities history. Schmid (1937), probably the most comprehensive collection of historical statistics and facts on the growth of the Twin Cities prior to the 1940s, presented four-dot graphs which illustrate the distribution of population for the two cities in the years of 1875 and 
1930, respectively. Unfortunately, these data were insufficient for our analysis as no data are available beyond the city limits, or for the years between 1875 and 1930 .

As direct population statistics are not available, a regional parcel data set is used in this study as a proxy. The data are maintained by the Metropolitan Council annually since 2002, and the data contain $\sim 1.07$ million parcel points throughout the seven county Twin Cities metro area (Metropolitan Council, 2008). Each point feature represents a parcel that is characterized by a standard set of attribute fields, although not all attributes are completely populated. The data set includes a 'year built' field which indicates the year the primary structure in a parcel was initially built. This field enables change analysis and time series investigations regarding the evolution of urban settlements in the Twin Cities. There are four 'use type' attribute fields that describe the first four uses of each parcel, respectively. If parcels have more than one building, the first (primary) building is displayed. The first field indicates the primary use type when a parcel has multiple uses. As our focus is on residential land use, residential parcels were extracted from the original data set for the analysis based on a parcel's primary use type. Another useful attribute field is 'FIN_SQ_FT'. This field records finished square footage of each parcel, which can be used as an approximate indicator of the intensity of residential land use. ${ }^{8}$

Although the 'year built' field of the parcel data allows us to extract the spatial diffusion of residences in the Twin Cities in a temporal process, these data cannot be used without caution. These data are troublesome on three counts.

First, this study approximates the 'snapshot' residential pattern of a particular year using currently existing residential parcels that had been built by this year. In doing so, we assumed the use type and residential area of all buildings have remained unchanged since they were initially constructed; we also ignored buildings that were torn down or replaced with new ones. Considering the intensive expansion and renewal that has taken place in the city centers, parcels in both downtowns were excluded from the analysis.

Second, residential density can be calculated as either the number of residential parcels or total finished square area of these parcels normalized by geographical area (in this case, we believe that the latter constitutes a better approximation of the intensity of residential land use). This calculation, though, does not differentiate an array of residential uses ranging from apartments, single family, multi-family to condominium. Further, only the current finished area is in the database, not the finished area at the time of construction; though the increase in finished area from the streetcar era to the present may be uniform throughout the region.

Third, a careful investigation into the parcel data set found that an abnormally large volume of parcels were coded as built in the single year of 1900 . We suspect it was caused by coding the dates of buildings constructed in an unknown year before 1900 as ' 1900 ' for convenience. In order to assure the accuracy of our analysis, observations before 1900 were excluded from this analysis, which eventually covers the period of

8 Unfortunately, this field is not populated for the 425,565 parcels in Hennepin County, where the city of Minneapolis is located. As a partial rescue, we acquired the Multiple Listing Service (MLS) data from Minnesota Association of Realtors. This data set contains real estate sale records during 2001-2004, which provides the finished square footage information for the parcels where a transaction occurred during this period of time. With the MLS dataset, we were able to fill the finished square footage information for 47,465 parcels in Hennepin, which account for $>10 \%$ of all parcels of this county. 


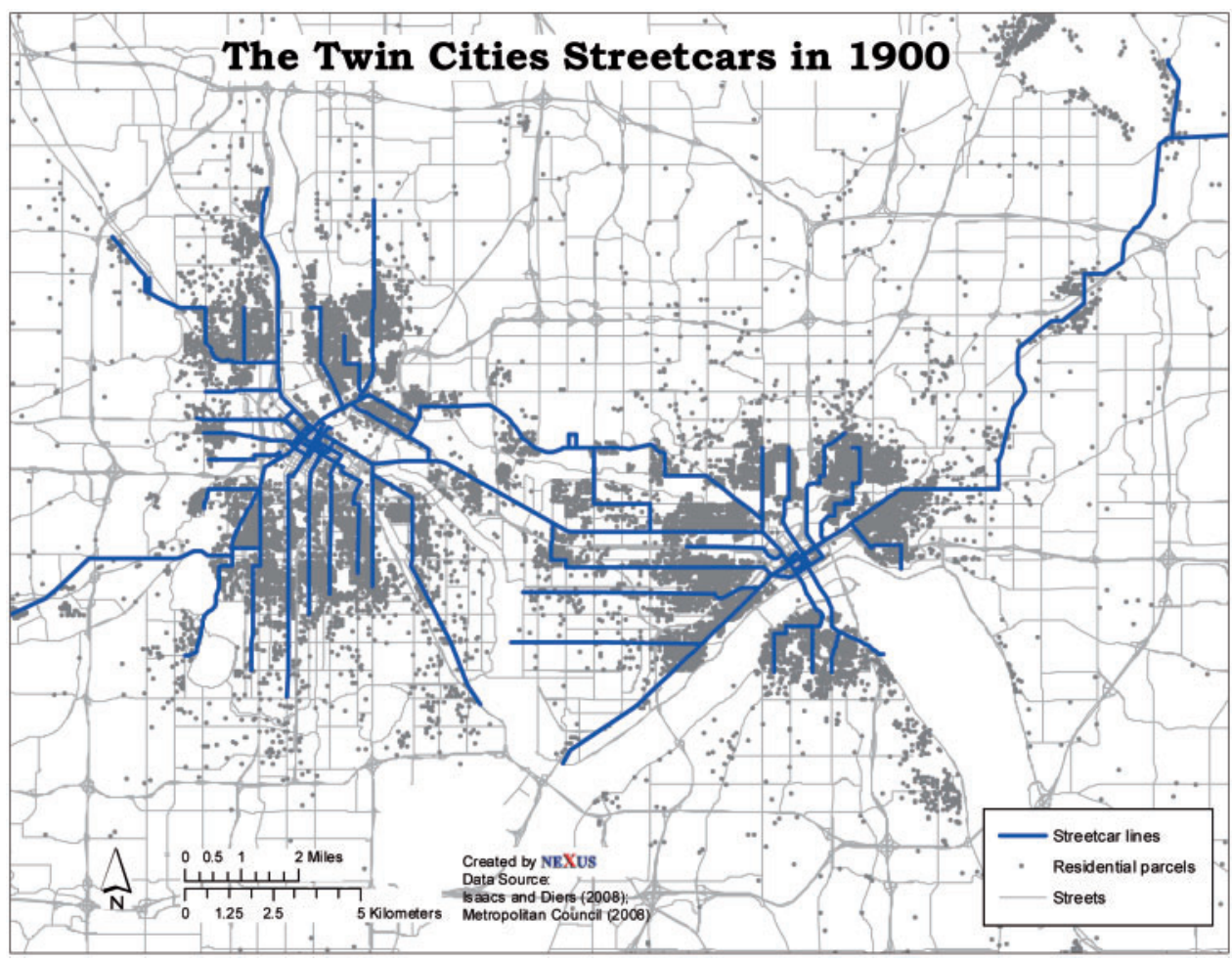

Figure 1. The Twin Cities streetcars in 1900.

1900-1930. The remaining data are consistent with census estimates of number of households by decade. ${ }^{9}$

With both streetcar and parcel data, we proceeded with replicating the temporal development of streetcar lines and residential land use in the Twin Cities. Figures 1-4 display four snapshots of the residential development coupled with the streetcar network in 1900, 1910, 1920, and 1930, respectively.

\section{Methodology}

\subsection{Residential density versus line density}

Two models were specified to predict residential density and streetcar line density, respectively. The results will be used to test our hypothesis on the reciprocal relationship between streetcar extension and residential land use development. A cross-sectional database was constructed at a tract level to estimate the two models. The metro area was divided into 606 tracts using the 1990 census tract boundaries (the 1990 boundaries were used because the seven counties region was not completely 'tracted' until the 1980s). Tracts that never had a single segment

9 This could be shown by regressing number of residential parcels to number of households in the seven counties with observations of $1900,1910,1920$ and 1930 . The resulting $R^{2}$ equals 0.99 . 


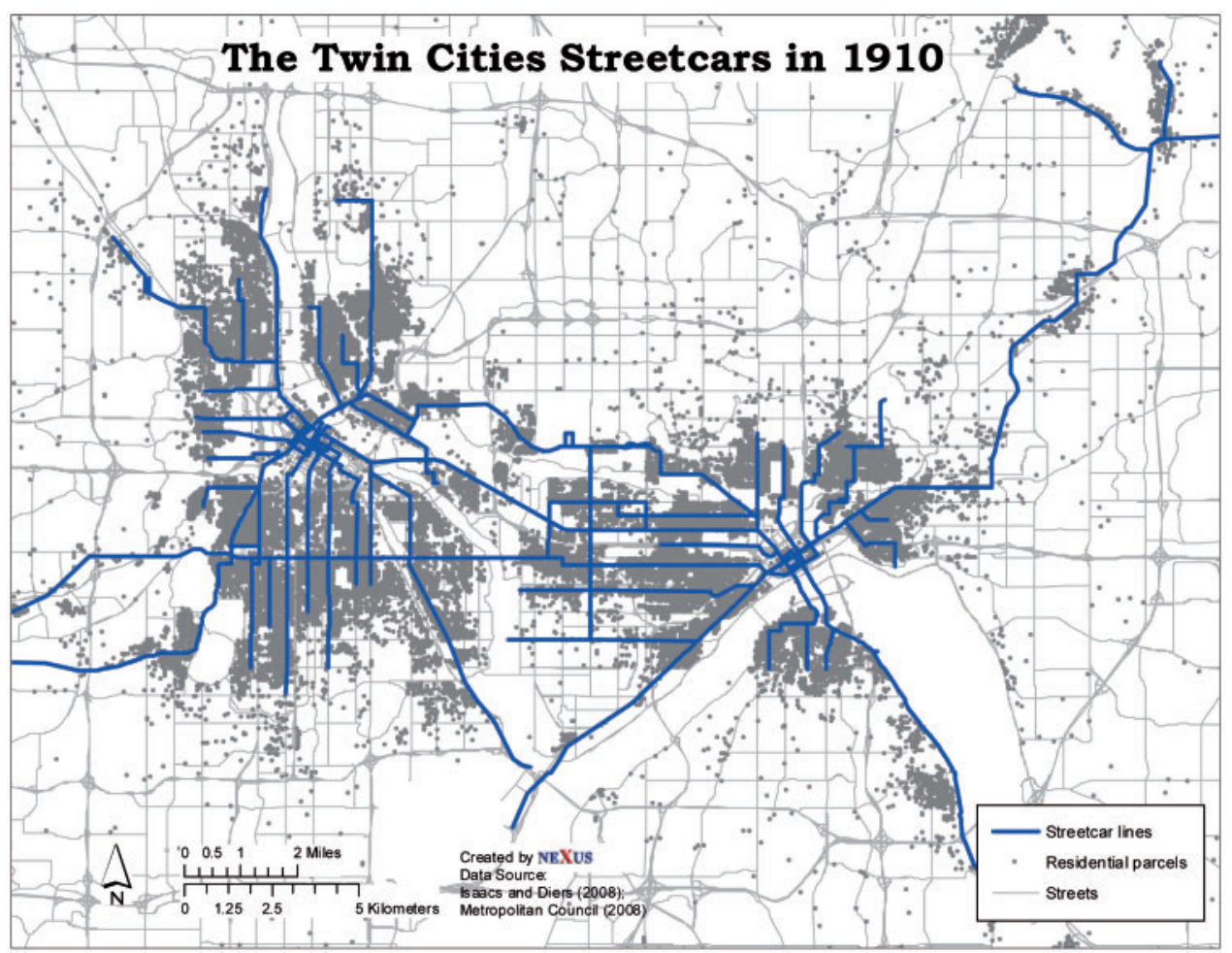

Figure 2. The Twin Cities streetcars in 1910.

of streetcar track laid down by 1930 were excluded from our analysis; tracts that intersect with either downtown were also eliminated for the previously mentioned reason. The remaining 356 tracts constitute the extent of the geographical area that was served by the streetcar network during the analysis period of 1900-1930. The cross-sectional time-series data were then constructed with observations of residential density and line density of each tract for each year between 1900 and 1930, respectively. ${ }^{10}$

With the data set established, the residential density model is specified as follows:

$$
\text { Model I: } R_{m, t}=\alpha_{0}+\alpha_{1} R_{m, t-1}+\alpha_{2} \Delta L_{m, t-1}+\alpha_{3} \Delta S_{t}+\alpha_{4} D_{m}
$$

where $R$ denotes residential density, $L$ indicates streetcar line density, $S$ indicates total residential area in the region, $D$ indicates the airline distance to the nearest downtown and $\alpha_{k}, k=0,1, \ldots, 4$ represent coefficients to be estimated. The dependent variable $R_{m, t}$ indicates the observed residential density for tract $m$ at time $t$. In order to conduct

10 The residential density of a tract in a specific year was calculated as total finished square meters of residential area constructed by the end of this year divided by the area of this tract. For those parcels in Hennepin County whose finished area information were not reported, the absent information was updated with the average of the parcels within the same tract. The line density of a tract, on the other hand, was calculated as the total length of line segments opened by the end of this year normalized by tract area. 


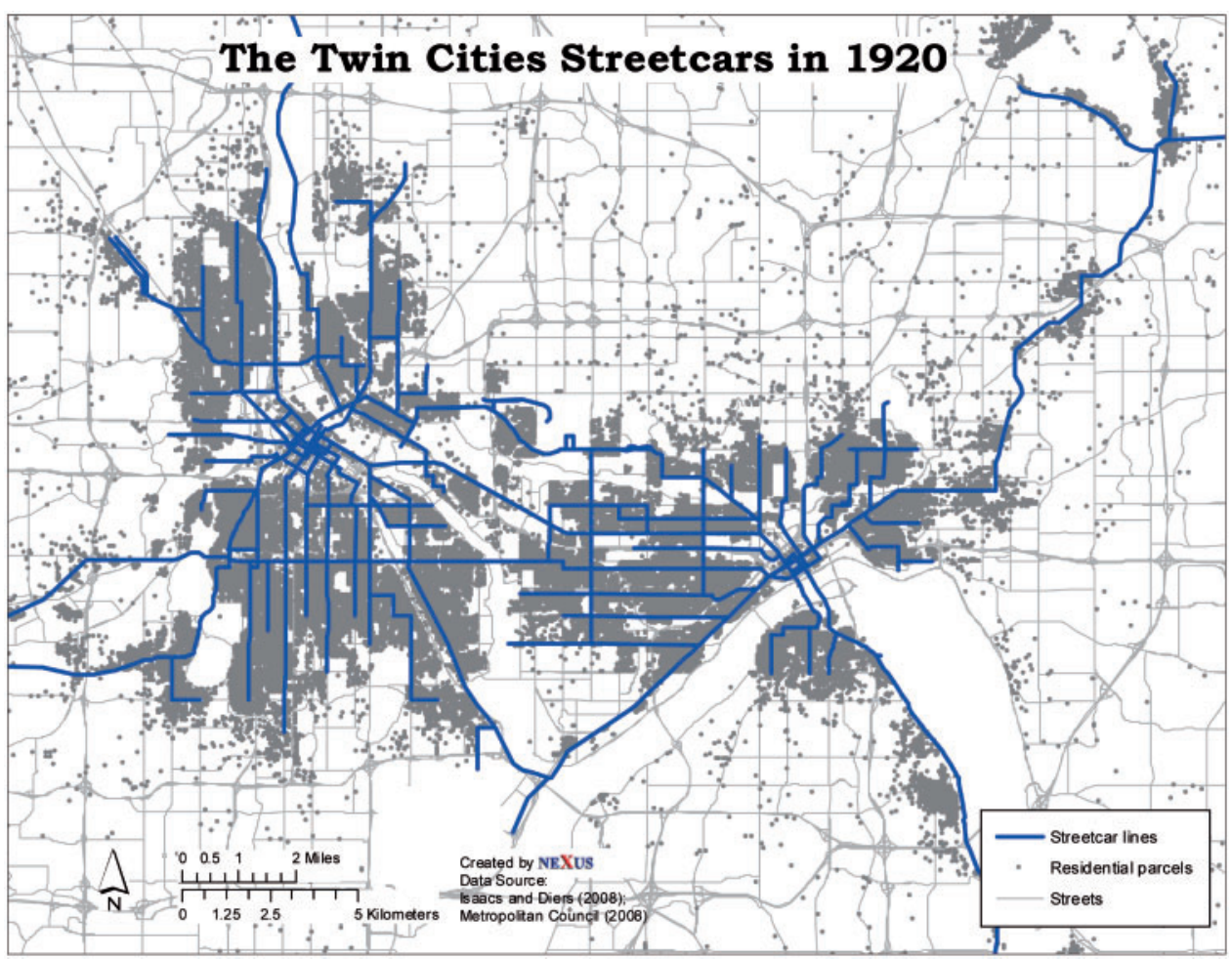

Figure 3. The Twin Cities streetcars in 1920.

a causality test, a lag structure is included, in which $R_{m, t-1}$ indicates the residential density at time $t-1$. The length of each time period is specified as 5 years. ${ }^{11}$ It is expected that the residential density at time $t$ can be largely accounted for by the lagged residential density of the same tract 5 years ago, so $R_{m, t-1}$ is included in the model as an explanatory variable, which also served to reduce the temporal autocorrelation in the model.

In order to test whether the addition of a streetcar line in a census tract has Granger caused the increase of residential density in this tract, a variable that indicates the lagged change in streetcar line density $\left(\Delta L_{m, t-1}\right)$ is also included in Model I. Although two or more lags could be specified, doing so did not improve the explanatory power of the model significantly.

There are other variables that may explain the temporal or spatial variations of residential densities. Some of those variables change over time but are common to all tracts, among which this model includes total residential construction that took place in the previous periods $\left(\Delta S_{t}\right)$ (measured by the change of total residential area from time $t-1$ to time $t$ ). Another set of variables is spatially differentiated but remains unchanged over time; in this model we include $D_{m}$, in particular, measuring the airline

11 A trade-off exists between capturing more time-dependent variations with a shorter time period and reducing the computation time with a longer one. With alternatives tested, a 5-year specification accounts for the majority of the variations in an affordable computation time. 


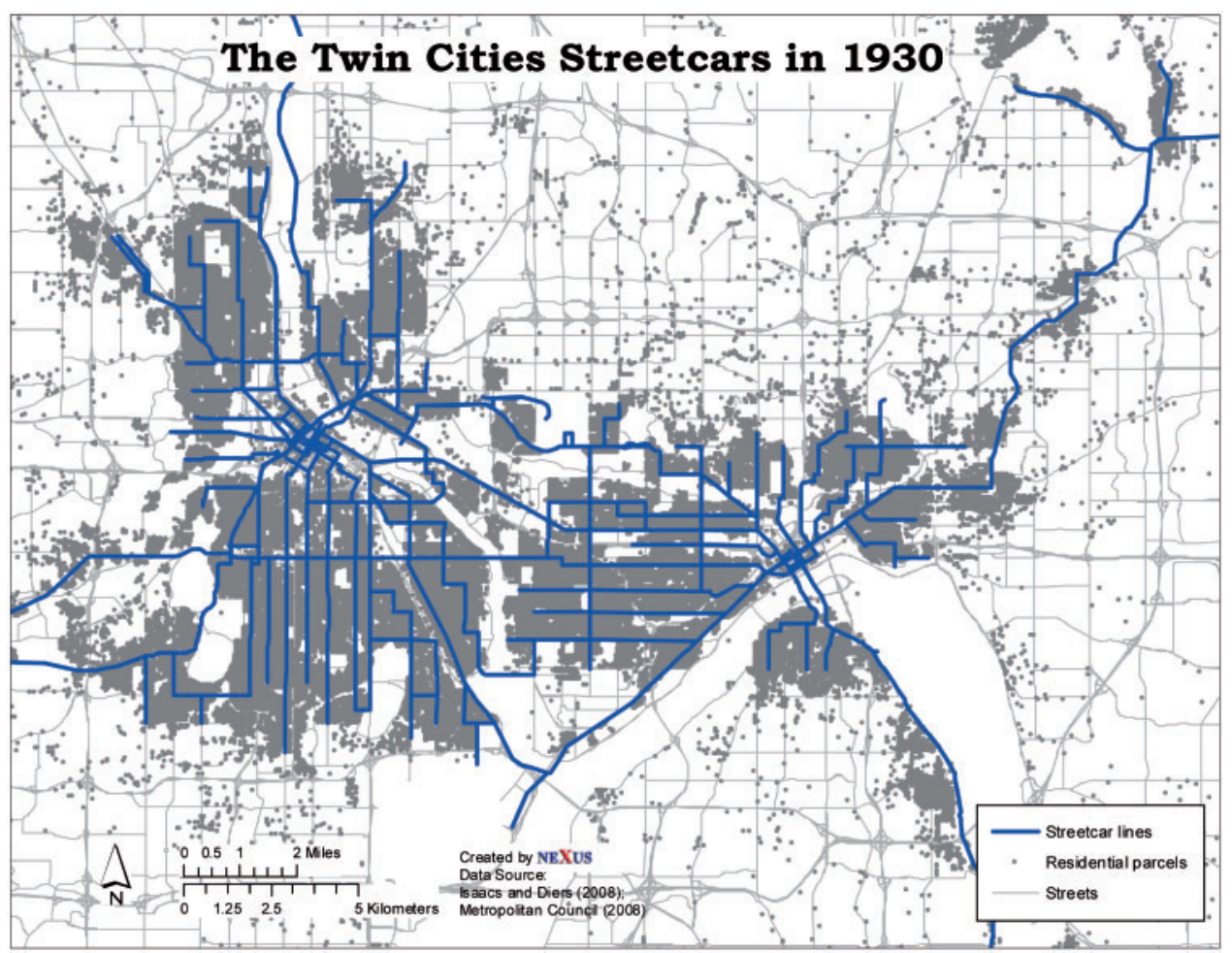

Figure 4. The Twin Cities streetcars in 1930.

distance from the centroid of each tract to the nearest downtown, assuming that the locations of both city centers are fixed through time. Similarly, another model is proposed to predict line density and to examine the causation effect on the opposite direction, namely, whether the increase of residential density had led to addition of streetcar lines. The model reads as follows:

$$
\text { Model II : } L_{m, t}=\beta_{0}+\beta_{1} L_{m, t-1}+\beta_{2} \Delta R_{m, t-1}+\beta_{3} \Delta E_{t}+\beta_{4} D_{m}
$$

where $\Delta E_{t}$ indicates the total length of streetcar lines deployed in the previous time period, while $\beta_{k}, k=0,1, \ldots, 4$ represent coefficients to be estimated.

Both models are estimated using the 'xtpcse' procedure in Stata SE 10.0, which calculates panel-corrected standard error (PCSE) estimates for linear cross-sectional time-series models.

\subsection{Proximity to line versus residential density}

Two models are proposed to test to what extent a neighborhood's proximity to the streetcar service had determined its residential density during the electric streetcar era of the Twin Cities. To conduct this test, a time-series panel data set had to be constructed at a finer geographical level (a census tract is generally too large to reflect the heterogeneity of neighborhoods within its boundary). In this case, we chose the 1990 census block boundaries, which divide the seven counties metro area into 36,825 blocks. 
For each time period, the residential density of each block is calculated as total residential area in the block normalized by block area, ${ }^{12}$ while proximity to the streetcar is approximated using the airline distance from the centroid of each block to the nearest streetcar line. ${ }^{13}$ To limit the data size, observations were extracted every 5 years rather than every single year between 1900 and 1930, inclusive, which accounts for seven time periods $(t=0,1, \ldots, 6)$.

Model III correlates residential density of a block with its proximity to streetcars in an OLS regression. The model is initially proposed as follows:

$$
\text { Model IIIa : } R_{n, t}=\gamma_{0}+\gamma_{1} D_{n}+\gamma_{2} t+\gamma_{3} P_{n, t}
$$

Observations on residential density and streetcar proximity for each block at a particular time (indicated by $R_{n, t}$ and $P_{n, t}$, respectively) present a 'snapshot' of the Twin Cities landscape. With data from all the seven periods combined, this model estimates the 'static' relationship between residential density and proximity to streetcars in the same time period by controlling $t$. As it is posited that the relationship may be different in the core versus periphery of the metro area, distance to the nearest downtown is also controlled.

A correlation test, however, disclosed that distance to streetcar lines and distance to the nearest downtown are highly and positively correlated (the correlation coefficient is as high as 0.92). While the close correlation between the two distance measures is itself interesting, it unfavorably caused collinearity in the model. We fixed the collinearity problem by replacing the continuous measure of $P_{n, t}$ with a set of dummy variables $\overrightarrow{p_{n}, t}$ which indicate proximity to the streetcar on a discrete scale. It translates into the updated model as follows:

$$
\text { Model IIIb }: R_{n, t}=\gamma_{0}+\gamma_{1} D_{n}+\gamma_{2} t+\Gamma \overrightarrow{p_{n}, t}
$$

where $\overrightarrow{p_{n}, t}$ represents a set of nine dummy variables and $\Gamma$ a vector of coefficients before the dummies. The dummy variables determine if a block is located within one of the following nine distance ranges: 0-400, 400-800, 800-1200, 1200-1600, 1600-2400, 2400-3200, 3200-4800, 4800-6400, 6400-8000 (with all distances measured in meters). This essentially allocates all the blocks into 10 ring buffers according to their relative proximity to streetcar lines. Each dummy variable is denoted by the upper bound value of its corresponding distance range. For instance, $p_{n, t}^{6400}$ equals 1 if block $n$ is located $4800-6400 \mathrm{~m}$ within the streetcar service at time $t$, and equals 0 otherwise. If a block is more than $8000 \mathrm{~m}$ away from any line, all the dummies will equal 0 .

The next model is specified as follows to examine whether the change in proximity to the streetcar service precedes the change in residential density:

$$
\text { Model IV: } R_{n, t}=\eta_{0}+\eta_{1} R_{n, t-1}+\eta_{2} \Delta S_{t}+\mathrm{H} \Delta \overrightarrow{p_{n}, t-1}
$$

To capture the potential causation effect, the model includes residential density of a block $\left(R_{n, t}\right)$ as the dependent variable, while the lagged changes in proximity measures

12 A block is dropped from the data if none of its parcels have residential area information.

13 It should be noted that in reality people generally walk along streets to access a streetcar. So network distance may be a more accurate measure of the actual proximity, we expect the numbers to be generally proportional though. Airline distance, however, is adopted because it is much easier to calculate, while still reflecting the relative distance away from streetcar lines. This distance is calculated using the 'near' analysis in ArcGIS. 
as explanatory variables on the right-hand side $\left(\Delta \overrightarrow{p_{n}, t-1}\right)$. Note that the change of a dummy variable equals 1 when distance to line is shortened to the corresponding distance range, and equals 0 when distance to line remains unchanged or changes within the range. Since no streetcar lines had been dropped by 1931, the temporal change in proximity measures will never be negative in our analysis period. This model also includes the change of total residential area $\left(\Delta S_{t}\right)$ as an explanatory variable.

As in the tract analysis, blocks that intersect either downtowns are eliminated. In order for a balanced time-series data, blocks whose residential density observations are incomplete (missing data in any of the seven periods) are also excluded. Finally a data set of 30,310 records (4330 blocks by seven time periods) is obtained, which is still too large for a PCSE analysis in Stata. This issue was addressed by randomly selecting $20 \%$ (866) of all eligible blocks for the analysis.

\section{Results}

The results from Model I and Model II are presented in Tables 1 and 2, respectively. As shown in Table 1 , residential density $\left(R_{m, t}\right)$ of tract $m$ at time $t$ is highly and positively correlated with five-period (5 years) lagged streetcar line density $\left(\Delta L_{m, t-1} . L 5\right)$ of this tract, suggesting the extension of streetcar lines (increase in line density) has caused a significantly increased volume of land devoted to residences 5 years hence. This finding corroborates our hypothesis that the deployment of streetcar lines, especially those extending into open vacant suburban land during the electric streetcar era, had brought new residents and new housing to the area they reached. In contrast, the lagged residential density $\left(\Delta R_{m, t-1} . L 5\right)$ is not at all a significant predictor of streetcar line density. Results from the two models suggest that the expansion of the streetcar system had to a significant extent led residential construction, and profoundly shaped the Twin Cities landscape. The results also support our hypothesis that unlike in those transportation systems whose infrastructure investment was made mainly in response to increased demand, the rapid expansion of the Twin Cities streetcar system was largely attributed to other factors such as superiority of technology, TCRT's monopoly ownership and close connections with the real estate business and reliance on streetcars for mobility during that era.

It is important to note that, changes in residential density are caused by many other factors not included in the estimated models above, such as housing type, land use type, land prices and values, inflation, etc. The purpose of this analysis, however, is to

Table 1. Model I: predicting tracts' residential density using lagged changes in line density

\begin{tabular}{lllr}
\hline Explanatory variables & Coeff. & Std. Err. & $P$-value \\
\hline Lagged residential density $\left(R_{m, t-1}\right)(\mathrm{L} 5)$ & 1.06 & 0.03 & 0.00 \\
Lagged change in line density $\left(\Delta \mathrm{L}_{m, t-1}\right)(\mathrm{L} 5)$ & 2.93 & 0.83 & 0.00 \\
Change in total residential area $\left(\Delta S_{t}\right)$ & $5.68 \mathrm{E}-10$ & $3.78 \mathrm{E}-10$ & 0.13 \\
Distance to nearest downtown $\left(D_{m}\right)$ & $1.38 \mathrm{E}-07$ & $7.99 \mathrm{E}-08$ & 0.08 \\
Constant & $5.91 \mathrm{E}-03$ & $1.32 \mathrm{E}-03$ & 0.00 \\
\hline
\end{tabular}

Number of observations, 3234; Number of groups, 154; Observations per group, 21; $R^{2}, 0.95$; Wald $\chi^{2}$, 2249; Dependent variable, $R_{m, t}$. 
Table 2. Model II: predicting tracts' line density using lagged changes in residential density

\begin{tabular}{lccr}
\hline Explanatory variables & Coeff. & Std. Err. & $P$-value \\
\hline Lagged line density $\left(L_{m, t-1}\right)(\mathrm{L} 5)$ & 0.96 & 0.01 & 0.00 \\
Lagged change in residential density $\left(\Delta R_{m, t-1}\right)(\mathrm{L} 5)$ & $-2.94 \mathrm{E}-04$ & $6.55 \mathrm{E}-04$ & 0.65 \\
Change in total line length $\left(\Delta E_{t}\right)$ & $4.49 \mathrm{E}-09$ & $2.71 \mathrm{E}-10$ & 0.00 \\
Distance to nearest downtown $\left(D_{m}\right)$ & $-1.02 \mathrm{E}-08$ & $2.66 \mathrm{E}-09$ & 0.00 \\
Constant & $1.03 \mathrm{E}-04$ & $3.45 \mathrm{E}-05$ & 0.00 \\
\hline
\end{tabular}

Number of observations, 3234; Number of groups, 154; Observations per group, 21; $R^{2}, 0.94$; Wald $\chi^{2}$, 11,736; Dependent variable, $L_{m, t}$.

Table 3. An OLS model that correlates changes in residential density of tracts with lagged changes in streetcar line density

\begin{tabular}{lccr}
\hline Explanatory variables & Coeff. & Std. Err. & $P$-value \\
\hline Lagged change in line density $\left(\Delta L_{m, t-1}\right)($ L5) & 12.10 & 0.67 & 0.00 \\
\hline
\end{tabular}

Number of observations, 3234; Number of groups, 154; Observations per group, 21; $R^{2}, 0.092$; Dependent variable, $\Delta R_{m, t}$.

examine whether change in streetcar line density is one of the factors that Granger cause the significant change in residential density (or vice versa), rather than build a comprehensive model that accounts for all influencing factors and predicts future residential density. To better judge the causation effect from streetcar line extension to residential development, the correlation relationship between residential density $\left(R_{m, t}\right)$ and lagged streetcar line density $\left(L_{m, t-1}\right)$ is examined, separated from all other factors. First-order differencing is taken on both variables to control the time effect (trend), so that the relationship could be examined in an OLS model as follows:

$$
\Delta R_{m, t}=\mu \Delta L_{m, t-1}
$$

Results are displayed in Table 3. The resulting $R^{2}$ of 0.092 indicates that the lagged change in streetcar line density $\left(\Delta L_{m, t-1}\right)$ can explain only $\sim 9 \%$ of total variance of the dependent variable $\Delta R_{m, t}$ (i.e. change in residential density). The fairly low $R^{2}$ suggests the limited explanatory power of streetcar line density alone in predicting residential development of the region. On the other hand, the coefficient and $P$-value for the explanatory variable imply that, despite its limited predictive power, change in streetcar density has a significant and positive causation effect on residential density. This is further corroborated in the plot of $\Delta R_{m, t}$ versus $\Delta L_{m, t-1}$. As can be seen in Figure 5, while the rather dispersive distribution of data points indicates a large fraction of unexplained variance with the only explanatory variable of $\Delta L_{m, t-1}$, the correlation between the dependent variable and the explanatory variable is self-evidently positive and linear, suggesting the existence of a significant causation effect between the two variables.

Table 4 displays the results from Model IIIb, which tests the 'static' relationship between residential density and proximity to streetcar lines in the same time period. Not surprisingly, residential density declines with distance to the two downtowns, 


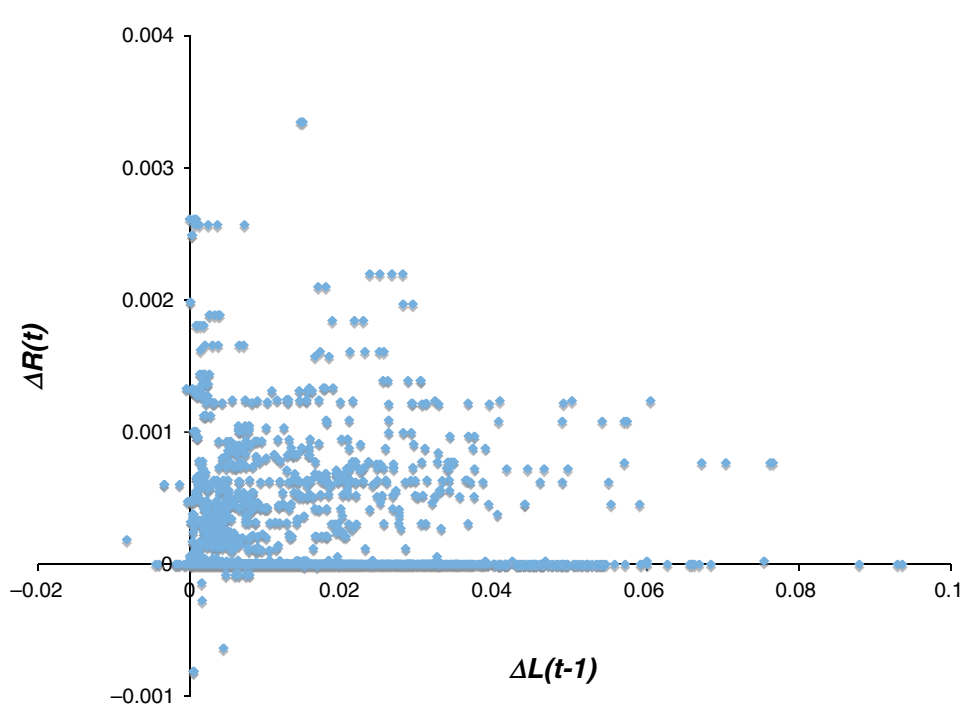

Figure 5. Correlating changes in residential density of tracts and lagged changes in streetcar line density.

Table 4. Model IIIb: correlating blocks' residential density with streetcar proximity measures

\begin{tabular}{|c|c|c|c|}
\hline Explanatory variables & Coeff. & Std. Err. & $P$-value \\
\hline Distance to nearest dowtown $\left(D_{n}\right)$ & $-1.41 \mathrm{E}-07$ & 7.90E-09 & 0.00 \\
\hline Time period $(t)$ & $1.68 \mathrm{E}-03$ & $3.23 \mathrm{E}-05$ & 0.00 \\
\hline \multicolumn{4}{|l|}{ Proximity to line dummies } \\
\hline Dummy $0-400 \mathrm{~m}\left(p_{n, t}^{400}\right)$ & 4.61E-02 & $2.72 \mathrm{E}-04$ & 0.00 \\
\hline Dummy $400-800 \mathrm{~m}\left(p_{n, t}^{800}\right)$ & $1.88 \mathrm{E}-02$ & $3.21 \mathrm{E}-04$ & 0.00 \\
\hline Dummy $800-1200 \mathrm{~m}\left(p_{n, t}^{1200}\right)$ & $4.62 \mathrm{E}-03$ & $3.60 \mathrm{E}-04$ & 0.00 \\
\hline Dummy $1200-1600 \mathrm{~m}\left(p_{n, t}^{1600}\right)$ & $-6.57 \mathrm{E}-04$ & $3.89 \mathrm{E}-04$ & 0.09 \\
\hline Dummy $1600-2400 \mathrm{~m}\left(p_{n, t}^{2400}\right)$ & $-3.21 \mathrm{E}-03$ & $3.28 \mathrm{E}-04$ & 0.00 \\
\hline Dummy $2400-3200 \mathrm{~m}\left(p_{n, t}^{3200}\right)$ & $-4.09 \mathrm{E}-03$ & $3.50 \mathrm{E}-04$ & 0.00 \\
\hline Dummy $3200-4800 \mathrm{~m}\left(p_{n, t}^{4800}\right)$ & $-4.22 \mathrm{E}-03$ & $2.84 \mathrm{E}-04$ & 0.00 \\
\hline Dummy $4800-6400 \mathrm{~m}\left(p_{n, t}^{64 t}\right)$ & $-3.59 \mathrm{E}-03$ & $2.98 \mathrm{E}-04$ & 0.00 \\
\hline Dummy $6400-8000 \mathrm{~m}\left(p_{n t}^{8000}\right)$ & $-3.72 \mathrm{E}-03$ & $3.07 \mathrm{E}-04$ & 0.00 \\
\hline Constant & $1.65 \mathrm{E}-03$ & $2.53 \mathrm{E}-04$ & 0.00 \\
\hline
\end{tabular}

Number of observations, 252,448; $R^{2}$ adjusted, 0.25 ; Root MSE, 0.03; Dependent variable, $R_{n, t}$.

implying much more intensive land development in the city centers than in the suburbs. The positive coefficients before time period $(t)$ suggest that residential density increases over years. With these two variables controlled, coefficients of proximity measures (dummies) are all statistically significant, and decline as the distance value increases, in other words, the nearer to streetcar lines, the more residential area developed. The coefficient before $p_{n, t}^{400}$, for instance, implies that per $10,000 \mathrm{~m}^{2}$ of land, 461 more square meters of residential area were constructed within $400 \mathrm{~m}$ of the streetcar lines than beyond $400 \mathrm{~m}$. Dummies within the distance of $1200 \mathrm{~m}$ are all positively correlated with residential density, while those beyond $1200 \mathrm{~m}$ are negatively correlated. This agrees 
Table 5. Model IV: predicting blocks' residential density using lagged changes in line proximity

\begin{tabular}{lllr}
\hline Explanatory Variables & Coeff. & Std. Err. & $P$-value \\
\hline $\begin{array}{l}\text { Lagged residential density }\left(\mathrm{R}_{n, t-1}\right)(\mathrm{L} 5) \\
\text { Lagged change in line proximity dummies }\end{array}$ & 1.04 & 0.04 & 0.00 \\
$\quad$ & $5.18 \mathrm{E}-03$ & $3.28 \mathrm{E}-03$ & 0.11 \\
Dummy 0-400 $\mathrm{m}\left(\Delta p_{n, t-1}^{400}\right)(\mathrm{L} 5)$ & $5.42 \mathrm{E}-03$ & $2.78 \mathrm{E}-03$ & 0.03 \\
Dummy 400-800 $\mathrm{m}\left(\Delta p_{n, t-1}^{800}\right)(\mathrm{L} 5)$ & $2.40 \mathrm{E}-03$ & $2.11 \mathrm{E}-03$ & 0.25 \\
$\quad$ Dummy $800-1200 \mathrm{~m}\left(\Delta p_{n, t-1}^{1200}\right)(\mathrm{L} 5)$ & $4.38 \mathrm{E}-08$ & $1.24 \mathrm{E}-08$ & 0.00 \\
Change in total residential area $\left(\Delta S_{t-1}\right)$ & $2.01 \mathrm{E}-03$ & $9.82 \mathrm{E}-04$ & 0.04 \\
Constant & & & \\
\hline
\end{tabular}

Number of observations, 4330; Number of groups, 866; Observations per group, 5; $R^{2}, 0.95$; Wald $\chi^{2}, 2153$; Dependent variable, $R_{n, t}$.

with our hypothesis that residential density will significantly drop beyond a walkable distance to access the streetcar, due to the lack of complementary transportation that would feed the streetcar service. This finding is also in agreement with the observation of 'finger-shaped' residential distributions in the Twin Cities.

The results from Model IV are reported in Table 5. It should be noted that one-period lag (L5) in this model represents 5 years of lag (which is consistent with Model I and Model II), as the block data were extracted every 5 years. As can be seen, the presented model includes only dummies with positive coefficients in Model IIIIb. This model presents the highest explanatory power among variations that include different sets of dummy variables. As Table 5 shows that residential density is positively correlated with the lagged changes in streetcar proximity measures, suggesting construction of a new line will Granger cause an increase in residential density. The causation effect, however, is not significant beyond $800 \mathrm{~m}$ (as the lag of $\Delta p_{n, t-1}^{1200}$ is not statistically significant in predicting residential density). This further corroborates our observation that proximity to the streetcar has a significant effect on residential development only within a walkable distance. Although both exhibit strong causation effects on residential density, it is a little surprising that gaining access to streetcar lines within $400 \mathrm{~m}\left(\Delta p_{n, t-1}^{400}\right)$ is not as significant a predicting factor as gaining access within $400-800 \mathrm{~m}\left(\Delta p_{n, t-1}^{800}\right)$. This might be explained considering that our analysis includes observations only during 1900-1930 due to the aforementioned data issue, while land development might have taken place substantially within $400 \mathrm{~m}$ of streetcar lines during the first decade of the electric streetcar era (1889-1899). The first $400 \mathrm{~m}$ might also be disproportionately commercial, as streetcars tended to run along commercial streets (and the streets along which streetcars ran tended to become commercial if they were not already).

\section{Conclusions}

This research analyzes causation in the coupled development of population and streetcars in the Twin Cities metropolitan area. Historic residence and network data were constructed during 1900-1930, and linear cross-sectional time-series models were estimated at both a tract and block level using these data. Granger causality tests disclosed that while the extension of electric streetcar lines preceded intensive residential development where streetcars reached, population growth did not predict line additions. 
This leads to the conclusion that unlike those transportation systems which were expanded in response to increased demand, the rapid expansion of the streetcar system during the electric era has been driven by other forces and to a large extent led land development in the Twin Cities. The main forces that have driven this process include superior technology, monopoly, real estate development and people's reliance on the streetcar for mobility.

Lacking alternative public transportation, proximity to streetcar lines became a crucial factor that determined where people live in that era. In analyzing the relationship between residential density and streetcar proximity, we observed that residential density declines with the distance from streetcar lines, and significantly drops beyond a walkable distance; we also observed that attaining streetcar service within $800 \mathrm{~m}$ (about a half mile) predicted the increase in residential density to a significant extent.

The implications of this research are several. First, the case of the Twin Cities streetcar system contributes to a deeper understanding of the supply-demand interaction in transportation. While the reciprocal relationship between population growth and transportation investment is pervasive, there are occasions when one significantly leads the other while the inverse process does not hold. The reasons could be technological, economic, managerial, social and even political. In fact, multifaceted forces have played out into a unique course of development for each urban transportation system. Second, the recognition of 'induced demand' and 'induced supply' effects are important for city and transportation planners to better understand and regulate urban transportation systems from a long-term perspective. Granger causality tests provide an analytic tool that can assist in examination of the presence and strength of both effects. Finally, transportation researchers have intrinsic interest in constructing models that can predict changes to transport infrastructure. This study presented empirical models that account for the temporal and spatial variations of population and transportation network in a integrated process, which may shed some light on the ongoing efforts.

Application of Granger causality analysis in transport geography provides a powerful mathematical tool to model and disentangle the causation effects between transportation and land use. The user, however, needs to be aware that this method is limited in several ways. Mathematically, Granger causality analysis normally presents linear regression, and can only give linear information of causal variables. More importantly, Granger causality is not 'causality' in a real sense. It tests if one thing happens before another thing, but in reality both things could be caused by a third variable which may not be included in the model. Therefore, a realistic formulation of a Granger causality model depends on appropriate selection of variables, which could not be divorced from a deep understanding of the real causation processes. In our case, hypotheses on the reciprocal causality between transit and residences in the Twin Cities arise from a comprehensive review of historical accounts, and the Granger causality analysis helps to capture some real causality and to analyze the significance of causation effects in the context of statistical regression. Last but not least, one needs to realize that not all the causation effects could be captured in one model. Obviously a causal factor that is not incorporated into a Granger causality model cannot be represented in the outputs. In this analysis, though we recognized that other factors such as land price, competing transportation modes, transit fare and service frequency may have played their roles in the co-development of residences and transit, we did not include these variables largely 
due to the scarcity of historical data. While our models incorporated realistically the maximum we can get from the available data and limit their focus to the reciprocal relationship between transit and land use, how the unexplained factors may have played into the causation processes deserves futher investigation in the future.

\section{Acknowledgements}

The authors would like to thank Mr John Diers for his help and constructive comments on our research. We also sincerely thank the two anonymous reviews who provided insightful comments on this article.

\section{References}

Adams, J. and VanDrasek, B. J. (1993) Minneapolis-St. Paul: People, Place, and Public Life. Minneapolis: University of Minnesota Press.

Axhausen, K. (2008) Accessibility: long-term perspectives. Journal of Transport and Land Use, 1: $5-22$.

Cervero, R. and Hansen, M. (2002) Induced travel demand and induced road investment: a simultaneous equation analysis. Journal of Transport Economics and Policy, 36: 469-490.

Corbett, M., Xie, F., Levinson, D. (2009) Evolution of the second-story city: the Minneapolis Skyway System. Environment and Planning, Part B (doi:10.1068/b34066).

Diers, J. and Isaacs, A. (2006) Twin Cities by Trolley: The Streetcar Era in Minneapolis and St. Paul. Minneapolis: University of Minnesota Press.

Fulton, L., Noland, R., Meszler, D., Thomas, J. (2000) A statistical analysis of induced travel effects in the US mid-Atlantic region. Journal of Transportation and Statistics, 3: 1-14.

Granger, C. W. J. (1969) Investigating causal relations by econometric models and cross-spectral Methods. Econometrica, 37: 424-438.

Green, H. and Truesdell, L. (1937) Census tracts in American cities: a brief history of the Census Tract Movement, with an outline of procedure and suggested modifications. Available online at: http://www2.census.gov/prod2/decennial/documents/21012490_TOC.pdf [Accessed 24 July 2008].

Hilton, G. W. and Due, J. F. (1960) The Electric Interurban Railways in America. Stanford: Stanford University Press.

Iacono, M., Levinson, D., El-Geneidy, A. (2008) Models of transportation and land use change: a guide to the territory. Journal of Planning Literature, 22: 323-340.

Isaacs, A. and Diers, J. (2007) Twin City Lines: The Streetcar Era in Minneapolis and St. Paul. Minneapolis: University of Minnesota Press.

Levinson, D. (2007) Density and dispersion: the co-development of land use and rail in london. Journal of Economic Geography, 8: 55-57.

Lowry, G. (1978) Streetcar Man. Minneapolis: Lerner Publications Company.

Metropolitan Council (2007) Historical transit routes - Twin Cities Metropolitan area. Available online at: http://www.datafinder.org/metadata/historical_transit_routes.htm [Accessed 24 July 2008].

Metropolitan Council (2008) Regional parcel dataset - seven county Twin Cities Metropolitan area. Available online at: http://www.datafinder.org/metadata/metrogis_regional_parcels.htm [Accessed 24 July 2008].

Olson, R. (1976) The Electric Railways of Minnesota. Minnesota Transportation Museum: Hopkins, MN.

Schmid, C. (1937) Social Saga of Two Cities: An Ecological and Statistical Study of Social Treands in Minneapolis and St. Paul. Minneapolis: The Minneapolis Council of Social Agencies.

Scott, D. M. and Horner, M. (2008) The role of urban form in shaping access to opportunities. Journal of Transport and Land Use, 1: 89-119.

Taaffe, E., Morrill, R. L., Gould, P. R. (1963) Transportation expansion in underdeveloped countries: a comparative analysis. Geographical Review, 53: 503-529. 
Timmermans, H. (2003) The saga of integrated land use-transport modeling: how many more dreams before we wake up?, Proceeding of 10th International Conference on Travel Behaviour Research, Lucerne, 10-15 August 2003.

Wachs, M. and Kumagai, T. G. (1973) Physical accessibility as a social indicator. Socio-Economic Planning Sciences, 7: 437-456.

Warner, S. (2004) Streetcar Suburbs: The Process of Growth in Boson, 1870-1900. Cambridge, MA: Harvard University Press. 